\title{
Development and implementation processes of digitalization in engineer-to-order manufacturing: enablers and barriers
}

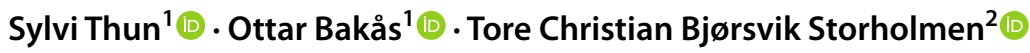

Received: 31 March 2020 / Accepted: 3 March 2021 / Published online: 18 March 2021

(c) The Author(s) 2021

\begin{abstract}
This study seeks to gain knowledge about key conditions in the process of digitalization using a socio-technical systems design as a theoretical framework and a case-study approach. Semi-structured interviews with 15 relevant stakeholders are conducted to learn about barriers to and enablers of the development and implementation process in a manufacturing company. After conducting a thematic analysis, eight higher-ranked themes relevant to the digitalization process are identified. These are grouped to describe the overarching phenomena, resulting in four enablers (shared trust, shared visual understanding, shared user perspective, and shared learning) and four barriers (trusting the system, understanding benefits, perspective of economics, and learning to manage scope). The study takes a holistic view of digitalization in its investigation of the development and subsequent implementation processes. The findings contribute to the literature via three key takeaways for stakeholders of a digitalization process in manufacturing. First, it is vital to understand and strengthen the role of the key enablers identified in this paper. Second, managers should observe and identify barriers in their own organizations, related both to technical and social aspects. Third, some of the enablers described in this paper can serve managers as helpful tools to approach the expected barriers to digitalization. This paper also challenges the research literature by arguing that research conducted on digitalization that sets new standards and premises for the working life in industry needs to use up-to-date socio-technical design concepts and theories.
\end{abstract}

Keywords Agile process - Democratic dialogue $\cdot$ Digitalization $\cdot$ Development process $\cdot$ Engineer-to-order manufacturing (ETO) $\cdot$ Industry $4.0 \cdot$ Implementation process $\cdot$ Social-technical system design

\section{Introduction}

Working life is in continuous change, and digitalization has been identified as a major trend affecting these changes. To be competitive, organizations need to find ways of coping with change, while at the same time, innovating and improving. The ongoing fourth wave of technological revolutions in manufacturing, termed Industry 4.0, sets new standards and premises for the working life in industry. There are numerous definitions of Industry 4.0 (Salento 2018); in this paper, it refers to a socio-technical system that reconfigures the relationship between people and organizations, technologies

Sylvi Thun

sylvi.thun@sintef.no

1 Technological Management, SINTEF Digital, Trondheim, Norway

2 Health, SINTEF Digital, Oslo, Norway and production systems, production, and consumption, and that proposes a new relationship between society and industry in a digitalization process (Cherns 1976; Mazali 2018). Many companies view digitalization as an enabler for greater competitiveness (Ferreira et al. 2019). Digitalization also has many definitions, but one overall definition that fits well with the context of our study is that digitalization refers to changes in the nature of work, roles, and business as a result of the adoption of digital technologies in an organization or in an organization's operational environment (Parviainen et al. 2017). Digitalization is about rethinking current operations from new perspectives that are enabled by digital technology (Parviainen et al. 2017).

How to handle digitalization while being competitive is not straightforward. To fulfil the potential for increased value, companies should ensure that their workers find digitalization useful and relevant. Sufficient, appropriate skills and competences are crucial to maintaining high productivity in the future. This is important in Norway, as it is 
a high-cost country where increased productivity can prevent outsourcing of workplaces. Companies need to take a proactive approach because the impact of digitalization will increase over the coming years (Parviainen et al. 2017). Digitalization of industry is expected to begin a phase of employment renewal that might be painful for some but will have a beneficial effect overall (Salento 2018).

As the focus on digitalization evolves, it is relevant to remember that digitalization is not an isolated phenomenon that occurs in a vacuum (Salento 2018). Digitalization affects the entire organization and its surroundings. However, discussion of the organizational and social effects of digitalization is still underdeveloped (Mazali 2018). The successful process of implementing new practices involves integrating several social and technological processes that are more or less complex (Landmark et al. 2019; Mazali 2018). An essential step in the development and implementation of new practices is to provide necessary and wellfunctioning solutions to all workers within the organization. An important assumption is, therefore, that manufacturing companies must facilitate digitalization so that operators understand the need for it and can take greater responsibility in their companies. If the interaction between technical and social structuring factors is not addressed, organizational transformations are less likely to be successful (Orlikowski 1996).

To gain a deeper understanding of the development and implementation of digitalization, socio-technical systems design (STSD) theory is an appropriate theoretical framework that focuses on the interplay between work, people, and technology, and on the involvement and participation of stakeholders. The framework does not have a one-sizefits all mentality. To take advantage of the positive effects of digitalization, companies need to ensure that the needs of people and social systems are respected and brought into balance with the advantages that technology offers. Consequently, there is a need for a deeper understanding of the development and implementation processes in digitalization, as well as of the consequences of the interfaces between humans, digital technology, and organizations. Knowledge about this can be developed by looking at what actually happens in digitalization projects. Hence, the objective of this study is to gain knowledge about key conditions in the process of digitalization using modern STSD as a theoretical framework and a case-study approach. By considering the previous research on enablers and barriers and the theoretical perspective of modern STSD presented in the theoretical perspectives, this article addresses the following research question (RQ):

What are the enablers to and barriers of the development and implementation process of digital applications in a manufacturing company?
We argue that research on the development and implementation process will contribute with knowledge about the possible gains of digitalization at different levels in an organization. Until now, there has been little empirical research on the barriers to and enablers of the development and implementation stage of digital applications and in particular, through the lens of modern STSD. A relevant notion of modern STSD when analysing digitalization cases, is that technology, work, and employees are components that together constitute the organizational work system, and that they need to be studied in terms of how they are connected, interact, and produce effects (De Sitter et al. 1997). There are only a handful of articles in the research literature that use modern STSD in studies conducted in Norway (e.g., Claussen et al. 2019; Haga 2019; Landmark et al. 2019; Ravn 2019). This article will also contribute with practical implications. For instance, it will highlight information about the introduction of digital applications into the environment of users. Our case-study approach will provide a sound empirical contribution to the field, which has thus been rather theoretical this far. This paper also adds to the small body of literature that has addressed digitalization in engineer-to-order (ETO) manufacturing companies. Empirical research conducted in manufacturing organizations is highly needed as it has become increasingly less visible in the scholarship (Salento 2018).

This study also contributes to the research literature using a modern STSD perspective, which is more relevant than ever for understanding how to balance the needs of human beings and social systems with the advantages and challenges digital technology offers (Claussen et al. 2019; Pasmore et al. 2018). Many organizations encounter the same challenges of staying agile while dealing with rapid change and growth. Most companies today need workers who can adapt, innovate, and apply new technologies to enhance the speed, quality, and costs involved in serving their customers. To attract workers with the capabilities of handling these changes, organizations need to make work that not only pays well but is also meaningful, challenging, and enjoyable (Pasmore et al. 2018). Using a case-study approach, we are able to study an organization during the digitalization process and to contribute with data about what really happens.

The structure of the article is organized as follows: in the theoretical perspectives, we address previous research on enablers and barriers of digitalization, followed by description of a socio-technical system perspective to look at factors likely to influence the digitalization processes of such organizational work systems. In the method section, we describe the case study, research process and ethical consideration. In the result section, we present the conducted analysis resulted in four main enablers and four main barriers. The findings are presented with exemplary quotes together with interpretations of the findings. A summary of the results is presented 
in one figure. Subsequently, we present a discussion of the findings, implication for practice, suggestions for future research, and concluding remarks of the paper.

\section{Previous research and theoretical perspectives}

\subsection{Enablers and barriers}

Manufacturing companies must improve their offerings to meet new industry standards and market requirements. The pace of change in market needs has increased because of advances in digital technologies (Abrell et al. 2015). The research literature has addressed some barriers relating to ongoing digitalization. Technology-related factors, such as technical problems, poor usability, low situation awareness, and increased qualification requirements, have been experienced as potential challenges when working with modern production technologies (Körner et al. 2019). Technical problems, particularly software problems (crashes, software errors, delayed system reactions to user input, and software freezes) have been described as frequently occurring stressors. Technical problems lead to interruptions, added time pressure, and multitasking in a negative way (Körner et al. 2019). The main consequences of these barriers are interruption of workflow and slowdown of the work process, which, in turn, increase the time pressure and perceived work stress. Technology-based demands, such as rapid changes in the production process and high complexity of the production system, together with organizational factors, such as lack of adequate training and the possibility of participating during the change process, affect the experience of work stress. Another barrier that is observed is that digitalization sometimes fails to reach the operational level. The process is top-down, and operators are less likely than managers to be satisfied with new digital tools (Thun et al 2019).

However, there are also positive effects of digitalization and some research findings have revealed its important enablers and potential consequences. Digitalization can provide benefits like increased transparency and agility of manufacturing operations, proactive optimization by dynamically generating action recommendation, knowledge sharing and delivery of (near) real-time information to both workers and supervisors (e.g., Gröger et al. 2016; Leyer et al. 2019), reduction in heavy physical work, faster work processes and improved flexibility, increased professional competencies, methodological competencies, and more opportunities for growth (Leyer et al. 2019). Digitalization can lead to better work preparation and a high level of awareness during the execution of work, a reduced coordination effort, avoidance of double routes, easy expert identification and contact, and different kinds of support (Leyer et al. 2019).
More specifically, digital applications can be used to increase the visibility of operations and performance status, to gain a systematic understanding of the system, and to make real-time decisions based on the context of the factory (Alexopoulos et al. 2018). In light of this, it is important to consider what the literature states as being enablers of such processes. Access to information (information and knowledge necessary to perform tasks), access to resources (assets in terms of money, material, and working time), access to support (by receiving guidance and feedback from colleagues and supervisors), and opportunities for advancement (learning opportunities to allow for knowledge and skills growth) are relevant enablers (Leyer et al. 2019). Other enablers are considerable effort and commitment at both the corporate and shop-floor levels, a thorough understanding of the information and communication technology infrastructure and corporate policy restrictions, and acceptance of solutions from team leaders and operators (Alexopoulos et al. 2018). It seems crucial that the aim of a digital intervention is well communicated with correct information and that there is a focus on continuous evaluation during the process (Lacueva-Pérez et al. 2018).

Four process-related factors enabling digitalization have also been identified: (1) process context; (2) process performance; (3) process knowledge; and (4) process communication (Gröger et al. 2013). Process context gives the worker information about the overall process, enabling the worker to understand the goal and its importance both for the company and for the individual's own role and tasks. Process performance provides workers with information that they can use to enhance self-optimization and decision-making by defining and measuring quantitative goals. Process knowledge includes execution of the process steps as well as continuous process improvement. Process information enables interaction among employees, both horizontally and vertically (Gröger et al. 2013).

However, realization of the potential of digitalization and Industry 4.0 to have positive effects on productivity, economic opportunities, and the future of work (Caruso 2018) is less straightforward than its vision. The link between technological innovation and increased productivity cannot be taken for granted. Improvements in workplaces are not determined by any technical innovation in itself, as technical innovation is always socially shaped (Caruso 2018). Digitalization is a social construct that is always partial and temporary, results from specific decisions, takes on different regulatory levels, and interconnects with contemporary economic and social dynamics (Salento 2018). Productivity gains will be achieved only by companies that adopt new forms of work organization at the same time as the new technologies (Valenduc and Vendramin 2016).

Another relevant point is that, when exploring digitalization processes, it is important not to ignore the relationship 
between those who have the power to design the processes (the designer/developers) and those who usually do not (the users) (Salento 2018). User involvement is essential for achieving well-designed technical innovations that meet users' needs and expectations. User involvement enhances user acceptance and eases system adoption by generating more usable solutions (Mumford 2006; Ritter et al. 2014). Development approaches that enable continuous delivery of software, such as agile approaches, provide new opportunities for users to be involved in the design process. There is also a growing interest in combining agile development with user-centred approaches to improve the collaboration between designer/developers and users (Abelein and Paech 2015).

\subsection{Theoretical perspective of the interaction between technology, work, and people}

Historically, STSD theory emerged as an alternative to the bureaucratic and Taylorist approaches whose universal principles regarded organizations as machines and workers as machine parts. The development of the STSD framework has had three distinct periods (van Eijnatten 1998). The rise of STSD has been defined as the socio-technical pioneering work period (1949-c.1959) and refers to findings from several studies, but mainly the well-known study of Trist and Bamforth conducted at the Tavistock Institute in 1951. Trist and Bamforth revealed that new technological equipment alone was not enough to create an efficient production system; rather, the key to an efficient production system is the creation of a good interaction between the technology and the organization. The second period (1959-c.1971) can be defined as the classical STSD, and the third period as modern STSD (1971-). However, there are three areas of common ground across these periods: (1) all have a multiple-stakeholders approach; (2) STSD is always associated with organizational purpose and strategy; and (3) in STSD, the work, the enablers of the work, the organization of the work, and the people are not separate domains (Mohr and Amelsvoort 2018).

The third period, modern STSD, can be divided into four traditions: (1) participative design (1971-); (2) integral organizational renewal (IOR; 1973-); (3) democratic dialogue (DD; 1979-); and (4) North American consultancy (1971-) (van Eijnatten 1998). During modern STSD, models and methods have been adapted to advances in systems theory and a necessary "do-it-yourself" method (van Eijnatten 1998). One of the traditions, DD has its geographical origins in Scandinavia, and especially in Norway. To a greater extent than process-oriented implementation, this tradition embraces processes characterized by DDs and local theory (Elden 1983; Raelin 2012). The foundation of DDs is the notion that to create good participative work roles, it is important that unions and other stakeholders participate in the learning process (Gustavsen 2018). What began as collaborative communication with unions has become collaboration with a wide circle of actors involved in DD. Gustavsen (2018, p. 196) stated: "If people can relate democratically to each other, they are expected to shape their material and organizational structures in a way that reflects democratic values." Important strengths of DD are the closeness to the field and the idea that collaboration and solutions should be created locally. Participative design and user-driven change are crucial in DD, and, in the last two decades, many actors have shifted from one-directional communication ("tell" and "inform") to proper two-way dialogue. This has been relevant for the development of modern DD (Gustavsen 2018).

In research, traditional STSD is still relevant, but it is important to remember that traditional STSD was developed in another industrial era and that both technology and social systems/organizations are in transformation (Claussen et al. 2019). Hierarchical structures and linear fixed processes for a linear production line, mining, and factory work, which involve routine and manual tasks, were highly relevant for the traditional concept of STSD and important for the development of the theory (Claussen et al. 2019). In 1983, Pava shared a (future-oriented) idea (Pava 1983, cited in Claussen et al. 2019) that highlighted more prominent use of an approach that emphasized reciprocal understandings and coalition formation. With the mix of work carried out in an organization, it is important to keep in mind that contemporary technical and social subsystems are directly related to and interwoven with humans, that several work tasks are technology-enhanced, and that we need to find functional practices (Claussen et al. 2019; De Sitter et al. 1997). Deliberations and discretionary coalitions have been suggested as ways to act (Pava 1983, cited in Claussen et al. 2019). Deliberations are discussions that come in more shapes than just regular meetings, conversations, or decisions; they are structures of reflective and communicative acts employed to resolve problematic issues. Discretionary coalitions are alliances of interdependent parties formed to make intelligent trade-offs that enable attainment of overall objectives. Different coalitions are associated with different deliberations (Claussen et al. 2019).

It is also possible that Norway has come so far with discussions and dialogue because of the country's long tradition of working with "indirect participation" at a national level. Another important element in practising DD in the workplace is autonomy (Gustavsen 2018). Compared to other European countries, Norway and the other Scandinavian countries have relatively high scores for autonomy (Tynes et al. 2018). Autonomy refers to control over aspects of task performance (Hackman and Oldham 1980; Karasek 1998). It is typically considered as positive, as bringing health and satisfaction to the employee who disposes of it, 
and as resulting in efficient work processes, profit, and satisfied clients for the employer who grants it (Mierlo et al. 2006, p. 282). Autonomy has also been shown to be relevant for industrial workers who need to handle the ongoing shift from repetitive, low-skilled, and physical work to more complex and cognitively demanding work (Gorecky et al. 2014; Hecklau et al. 2016; Kagermann et al. 2013; Prinz et al. 2016; Tortorella et al. 2018).

\section{Research methodology}

\subsection{Case-study approach}

To study the actual development and implementation process of digitalization in a real-life ETO manufacturing context, a case-study approach was chosen. Case studies are considered suitable when the research is of an exploratory nature and the researchers are investigating current and evolving topics. As stated by Yin $(2009$, p. 14), case studies are "an empirical enquiry that investigates a contemporary phenomenon in depth and within its real-life context, especially when the boundaries between phenomenon and context are not clearly evident".

A single case study was chosen so that the complex nature of digital transformation processes in a large ETO manufacturing company could be understood. Field-based studies can extract rich data and deeper insights from actual practices. Case studies enable researchers to generate deeper understanding of the phenomenon within its real-world context as well as new knowledge and theory (Eisenhardt and Graebner 2007). The aim of this case study is to better understand the enablers of and barriers to the digital transformation that the organization is currently undergoing.

Three criteria were identified to guide the selection of the case company: size and complexity, experience level, and access. We wanted to find a case company with sufficient size and complexity to provide a rich understanding of opportunities and challenges when implementing digitally enhanced tools. Second, we wanted a company that has had sufficient experience with digital transformation projects. Third, we wanted to work with a company where we could access a broad range of informants who represented multiple roles in a digitalization project, including top-level management, different technical development roles, union representatives, and end users.

The case company was selected from an ongoing industrial research project. This was a four-year research project that started in 2016 with the aim of better understanding how to improve productivity and efficiency within ETO supply chains. The core of the project involved developing a company-specific production and improvement programme for the company. By designing mechanisms for operations and improvement based on simplicity and agility, the goal was to enable improved collaboration between different professions, project stages, and actors. The use of increased digital support for operations and continuous improvement has been central for the case company throughout the project.

\subsection{Case company}

The case company is a large supplier within the oil and gas industry in Norway. The company has about 2,800 employees and its turnover in 2018 was about 600 million euros. The company plans and executes demanding engineering, procurement, construction, and installation projects, which are a common form of contracting agreement within offshore construction. The company supplies a wide range of personnel for the construction of offshore oil platforms and land-based process facilities.

The case company is a contractor of such projects, which means that it does the work partly using its own labour and partly by subcontracting. When it comes to design, engineering, and procurement, the company depends on an engineering partner to do most of the work, while construction involves a large number of subcontractors, suppliers, and staffing companies, as well as its own facilities, leaders, and operators. Installation could be part of project agreements or as options contracts. Hence, it is not only the product itself that is highly complex, but also the project organization and its value chain are also highly complex.

The company has long history of developing and exploiting digital tools to manage their projects. However, in the last three years, exploiting new technologies has received increased attention. The company has developed a broad digitalization programme that encompasses different Industry 4.0 technologies, with a roadmap comprising more than 25 planned and ongoing projects for enhanced technological support of operations and improvement activities. The roadmap is structured according to seven categories that cover different phases of an offshore project: automated project setup, automated engineering, digital lifecycle information, digital procurement, digital yard, robotics, and digital project management.

For this research, we studied two of the company's digitalization projects in detail. These projects are a "Digital Improvement System" and "Mobile Work Packages" (our translations). Both projects adopt an agile development approach and utilize user-centred principles to facilitate user involvement in the development and implementation process (Fig. 1). The Digital Improvement System encompasses a mobile application for improvement suggestions, as well as a back-office system to manage improvement projects (from small to large). Mobile Work Packages is a mobile application for managing job orders, work allocation, and teams in manufacturing, and it collects all information relating to 


\section{PROJECT \\ DEVELOPMENT \\ IMPLEMENTATION}

Agile development using Scrum

and user-centred approaches

Agile development using Scrum and user-centred approaches
Train the trainer approach, training courses, user manuals, etc.

Train the trainer approach, web based training, training courses, user manuals, etc.

Fig. 1 Overview of the two studied projects and their development and implementation approaches

a job to be done, including drawings, instructions, material lists, and time estimates. These have traditionally been distributed through foremen (team leaders) and kept in hard copy in folders, making it time consuming to update and perform revision control. The mobile application allows for better information sharing and coordination of work.

\subsection{Data collection}

The qualitative data were mainly collected through semistructured interviews. Fifteen interviews were conducted in total. Most of the interviews were performed face to face, while video conferences were used for two of the interviews for the convenience of interviewees who were travelling. Each interview lasted between 45 and $60 \mathrm{~min}$.

The interviews were performed in two phases with different interview guides and objectives. The first round of interviews (six sessions) covered four main topics: inspiration for digitalization, development and implementation processes, new opportunities from digitalization, and future opportunities and barriers. In these interviews, the informants were encouraged to use examples from the Digital Improvement System and Mobile Work Packages projects, but they were also allowed to provide experiences from other initiatives. The second round of interview (six sessions) went into more detail on the design, development, and implementation processes of the Mobile Work Packages. The third round of interviews (four sessions) focussed on the experience of the project super-users. The super-users were regular employees (foremen and operators) with a dedicated role to interact with the development team. They were selected to represent a variety of the workforce, both in terms of age, profession, and technology skill set, and contributed to all development stages. Sharing domain expertise and work practices, participating in workshops, answering questions from the development teams, and taking part in application testing were some of their expected tasks.

The 15 informants had the following roles in the company:

- Yard director

- Manager of the digitalization programme

- Union representative
- Foreman

- Manager of logistics

- User experience designer

- Software developer A and B

- Industrial researcher

- Software test manager

- Project manager

- Super-user A, B, C and D

Each informant was numbered from 1 to 15 , in random order rather than according to table above, as a measure to maintain the anonymity of the informants. The format "INF.1", "INF.2", and so on, will be used in the results section to denote quotes from the different informants. One of the informants was interviewed twice in two separate sessions, covering different aspects of the digitalization process.

\subsection{Data analysis}

Collected data from the interviews were analysed using a coding and categorization scheme. The first step was to select data from the interview, looking for statements that were related to enablers of and barriers to digital transformation. We selected statements from the material that matched one or more of the following criteria:

- Concepts that were used often

- Interesting or unexpected data

- The interviewee stated explicitly that it was important

- The information matched with findings in literature

The categorization of data from interviews followed a thematic analysis approach (Braun and Clarke 2006). First, the transcribed material was reviewed according to the above criteria on enablers and barriers. The quotes that were selected then comprised our A-level statements. These quotes were then grouped into categories with a higher level of abstraction (level B). The findings in the $\mathrm{B}$-categories were then reviewed against the theoretical foundation. This practice involved collaboration among the three authors to ensure a common view of what the data material was telling us. Next, we identified 20 C-level categories, 10 each for enablers of and barriers to the 
digitalization process. These were grouped to describe the overarching phenomena that could be identified. In the final step, we further synthesized the enablers and barriers down to eight key aspects, four each for enablers and barriers. This last step was conducted based on three sources of input. The first input source was from other scholars throughout the review of this article. We also had further discussions among the team of researchers for the project. Finally, we compared the C-level categories to aspects described in the literature, and to the relation between potential enablers and the barriers. The results of the data analysis in the case study are summarized in Sect. Results" below.

This form of thematic analysis is a common research method within social sciences but does not come without limitations. There are risks of biases, in the sense of misinterpretation of statements or seeking connections between topics that are unrelated. The measures taken to overcome the risk of bias involved sending the summary of interviews to representatives in the company, as well as allowing the research team enough time to discuss the different constructs.

\subsection{Ethical considerations}

All participants received a written information letter about the study, its purpose, and how data would be used and stored. Furthermore, it was highlighted that participation in the study was voluntary, and that participants would be anonymous. The use of random numbering to disconnect the roles of the informants was a further step to ensure anonymity. A signed informed consent form was required before participation. In addition, the Norwegian Social Science Data Service approved the study.

\section{Results}

The conducted analysis resulted in four enablers and four barriers. The enablers relevant to the development and implementation processes in a manufacturing company, and which were derived from the data, are shared trust, shared visual understanding, shared user perspectives, and shared learning. The relevant barriers are trusting the system, understanding the benefits, perspectives of economics, and learning to manage scope. The theoretical lens in the conducted analysis are modern STSD and in particular DD. Therefore, findings of enablers and barriers also show how different ways of DD can play out in digitalization projects. The findings are presented in Fig. 2 and further elaborated in the following subsections.

\subsection{Shared trust}

The first enabler presented is shared trust and consists of themes addressing the building of trust, extended collaboration with unions, and transparency of purpose.

A good feedback loop together with a widespread involvement and inclusion are central to building trust in a development and implementation process. In the studied case, the structures for input, information, dialogue, and feedback were important, and especially the confidence that inputs would be considered and receive feedback (which, all together, is called a good feedback loop). One participant stated: "To have structure on where input is to be given and feel that input is included" (INF.7).

Another aspect of "building trust" in a development and implementation stage is honesty and transparency about the project aims and the awareness of misinterpretations. In the case company, we observed different reflections about project aims depending on a respondent's position. Those higher up in the company were confident that the digitalization projects were crucial and positive, while those on the shop-floor level experienced more insecurity. Some individuals might fear losing their jobs or might be concerned about new and more challenging (extra) tasks in an already demanding work setting: "We need to reduce fear of job loss, increase focus that there will be changes in roles, but not job loss" (INF.9). Several informants addressed the potentially dramatic consequences of how digitalization processes can change the content of their work: "The strategy is that I become unemployed" (INF.6). Further, digitalization processes not only could alter work content, but could also affect workload: "It is a digital solution that is suddenly making changes so that those who work with planning now need to enter a new discipline, and then get an extra workload" (INF.8). The ability of a company to build trust about the process by creating good structures for information and feedback, together with openness about aims and awareness of different interpretations, becomes a criterion for successful development practices.

In the case company, there is a long tradition of professional collaboration with unions. We observed that this tradition amounted to more than just a basic minimum of collaboration, but was rather something embedded "in the walls" of the company: "We have unions doing their job, and I think that it is more important than all digitalization! That the company has a good cooperation with the unions. That cooperation is more important than any digitalization. We relate to the book [work regulations]" (INF.6). This longstanding and appreciated collaboration ensured that the company was able to handle different kinds of challenges and modes of collaboration robustly. The company had the capacity to adopt a different mindset in its industrial relations. The management and unions can shift from "heated" 
Fig. 2 Enablers of and barriers to the development and implementation process

\section{Development and implementation processes of digital applications in ETO manufacturing}

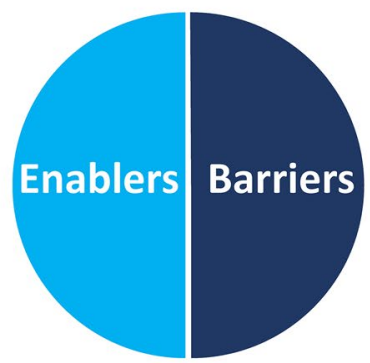

\section{Shared visual understanding Visual mapping and structuring Visualization facilitates participation}

\author{
Shared user perspectives \\ Flexible and versatile involvement \\ Rapid release of functionality \\ Communicating user needs
}

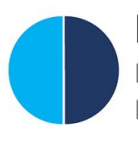
Perspectives of economics Budget change Economic conditions

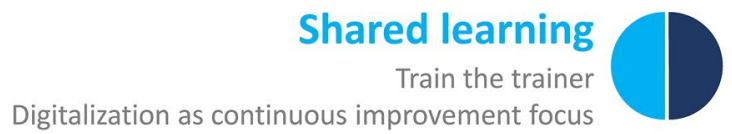

Learning to manage scope

Large-scale implementation and training Managing user feedback dialogue in one case to collaborative dialogue in another. There is room for heated discussions and disagreement. One of the participants highlighted the "high level of tolerance to provide input and discussion. The input may not be the conclusion, but they [the input] will be heard and evaluated" (INF.10). This collaboration is one strategy the company uses to gain an understanding of the needs at the various organizational levels, from the floor level to the top management. An extended collaboration with the unions is an indispensable structure:

When things are going well, you may not need it [industrial relations] as much, but when things are going badly, it is important that these structures are in place - they are really important structures for most things. (INF.10)

A voluntary contract initiated by the company was created to ensure the workforce knew what was going to happen during the mapping. This was done in collaboration with the union representatives. By doing this the company informed the workers that all participation was voluntary and that this was not an evaluation of them, but a project for greater good. (INF.4)

An extended collaboration with unions allows a broad agenda of discussions and learning points and acts as an enabler in the development and implementation process. We observed that all informants, regardless of position, appreciated this extended collaboration that was rooted in their company's practices.

The basis for succeeding with the development of digitalization projects is to get a collective understanding of why the initiative is undertaken. In the case company, it was found that the purpose of a digitalization project had to be communicated clearly. One of the informants stated: "In the development phase it has been important to be clear and honest about the purpose of the project. This way, having open communication early on is important" (INF.9). This was supported by another informant who emphasized that the underlying strategy must be communicated: "Openness about what the strategy is has been vital” (INF.6). The startup phase of digitalization projects often requires important 
clarifications about factors such as the goal, objectives, methodology, team, form of collaboration, and technology partners. This topic was further underlined by the informants: "Critical clarifications in the initial phase have been crucial in order to create a good process" (INF.9).

\subsection{Shared visual understanding}

The second enabler presented by our analysis concerns visual mapping and structuring, and how visualization facilitates participation.

Visualization was found to be key to achieving good results in the two digitalization projects. As part of the initial mapping processes, the project team used observations and shadowing, photo and video recording, and interviews with users to gather data. A broad set of tools for documenting work practices was used: "Disposable cameras were handed out to the workers to document their working day. Further, a WhatsApp group was used to gather live data and images from multiple users. We also held co-creation workshops to discuss the findings" (INF.5).

The project development teams later used visualization for mapping out and structuring the potential use cases of the applications. Visual user journeys were prepared to structure a typical day for an operator and a foreman, presenting and highlighting issues or areas for improvement. This made it easier for foremen and operators to comment if crucial elements were missing or if the suggested user journeys did not reflect the reality. The user experience (UX) team used the same visualization approach when prototyping the application interfaces. These prototypes presented different screens of the application, visualizing what the application would look like and how to interact with it. Prototypes were presented both to users (for testing and feedback) and to developers prior to the programming. The visualization prepared by the UX team was especially of value for the programmers, as the latter could focus on programming rather than on suggesting designs and interaction principles. "It is easier to do the programming and find the solutions when you see the UX design. It enhanced the understanding of the task that the development team were trying to solve and why this had to be done" (INF.5). During testing and feedback sessions, the illustrations made it easier for users not only to comment on the interface, but also to bring new suggestions to the table. We observed that visualization made the participants more confident to share and discuss important details and artefacts of their workday that had an impact on the applications content and layout: "Having something visual is critical for providing feedback. To see something practical is important; it is hard to imagine functionality without seeing it" (INF.1) (Fig. 3).

A key finding was that almost all the informants emphasized the importance of using visualization in the development stage of the digitalization projects. For example: "using visualization has most definitely been one of the key success factors in the project" (INF.1). Applying visualization early on made it easier for users and programmers to proceed towards a common goal.

An important topic raised by most informants was that using visual communication enabled better participation in the development phase of the project. In many development projects, consideration of the look and feel of a system is introduced in later stages. In the case company, it was strategically decided to involve UX experts from the outset to improve communication: "We wanted to involve UX (user experience team) from the first day to ensure knowledge

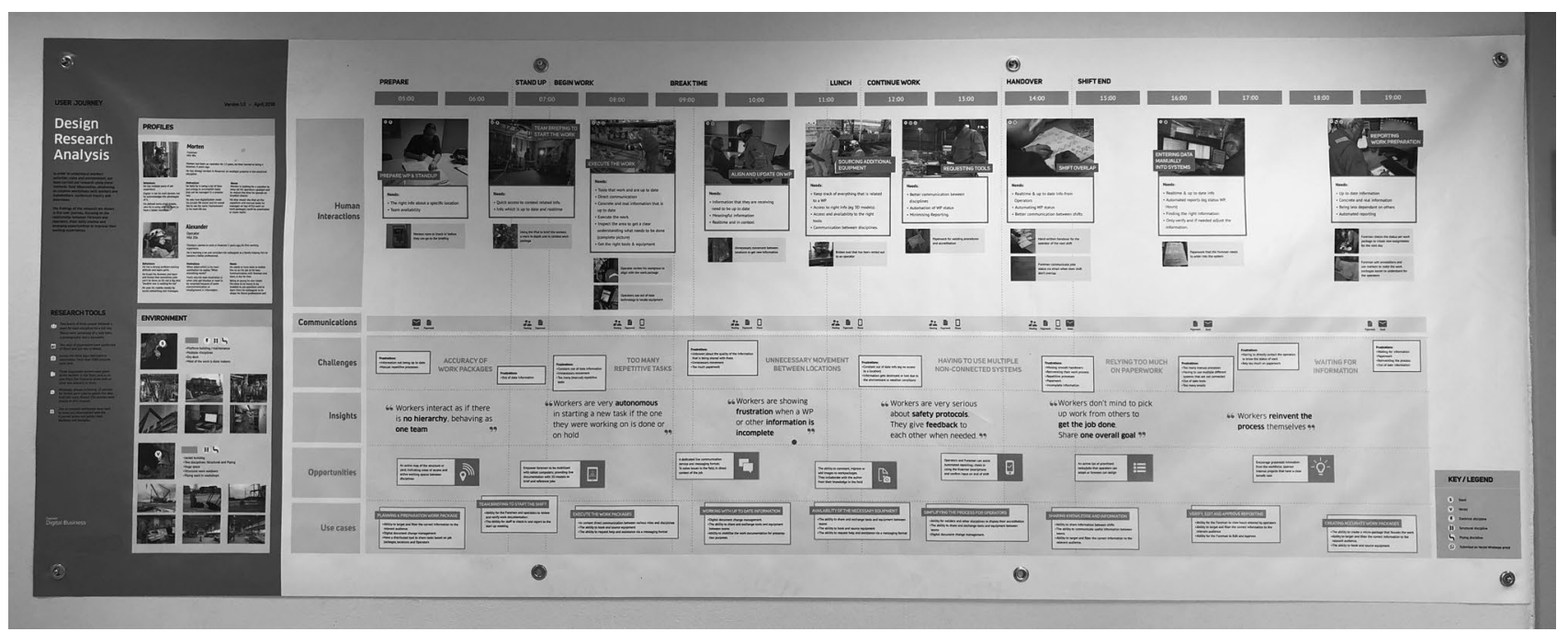

Fig. 3 User journey visualizing the research analysis 
transfer. UX would typically start later in many projects" (INF.4). By being involved from the beginning, the UX team could utilize visualization in the mapping, structuring, and prototyping stages, thereby enabling operators and non-specialists to contribute with their opinions. Involving the UX team in the initial mapping also ensured knowledge transfer in the project. In many development projects, the UX team is introduced after the mapping has been completed, which makes it more challenging for the team to gain the necessary insight into user needs and context of use.

\subsection{Shared user perspectives}

The third enabler, shared user perspectives, addresses topics such as the flexible and versatile involvement of stakeholders in particular end users, rapid release of functionality, and communicating user needs.

In the case company, crucial enablers in a development stage are the mapping of user needs on the floor level, obtaining first-hand suggestions, and, above all, receiving information from the end users. Participants addressed these enablers in the following ways: "The company has been good at involving end users, and we have had relevant user representatives in each case" (INF.10). One informant highlighted the need for extended involvement by "more than the law 'requires'. Involvement is a prerequisite for success" (INF.9). This article highlights the importance of a flexible and versatile involvement practice, both during development and implementation of digital solutions. However, in some cases, there are stakeholders other than end users who need to or should be involved. The practice of flexible involvement was observed as there were many ongoing digitalization projects in the case company running in parallel: "We have different [project] sizes, some with a handful of users and up to 1,000, then there will be a subset of those involved. Focus on involvement as much as possible. We have a high degree of user involvement" (INF.8). User involvement or a user-centred approach seems to lead to better solutions.

All participants mentioned that versatile user involvement was an enabler of the success of the development process they had been involved in or had heard about in their company. This was also reported by an external development partner:

Having presentations with the users every other week was time consuming. ... These visits affected the shaping of functions and the design of the app. Its time consuming for sure, and you get less time to develop. From a designer point of view, you need to be a bit humble; the workers know best. The know what they need.... Overall, the benefits of working like this have been way better than the challenges (INF.4)
Also, relevant to embracing a shared user perspective is the focus on internal resources and the importance of an internal project leader: "Internal project manager who knows our processes and the network internally, which pushes us to respond and participate" (INF.1). It is important that an internal project leader has the resources (work time) to take responsibility and facilitate feedback and communicate with all participants, both internal end users and the external project team. Having an internal leader with knowledge of the local context is crucial and makes it easier to achieve good communication during development and implementation stages. The case company has had long experience with digitalization projects, and we observed that the informants reflected on previous practices by giving us examples of previous projects and how they had learned that involvement in the process is crucial.

Both cases studied in this article followed an agile development approach that consisted of extensive user involvement throughout the processes. This included mapping of user needs, co-creation workshops, and sessions for testing and feedback. Both projects focussed on iterative development with rapid release of functionality:

Unlike traditional development, you don't have to have all solutions ready when presenting functionality to the end users. If you wait several years to present the final solution, you run the risk of not meeting the users' needs and expectations. (INF.5)

We observed that this development approach led to a mutual understanding between developers and users, which eventually led to better solutions. Using iterative development and allowing users to continuously give feedback, it was possible to detect challenges and make corrections at an early stage. One informant's response exemplified this:

We've all provided input all along the way, and when it gets rolled out to the rest, it's going to get even more input. With an increased number of users, there will be more people seeing ways to improve and streamline the app. We've managed to change several things, e.g., how to report progress. We are getting a new overlay now, because the old one was too cluttered. (INF.14)

The project development teams took several measures to ensure continuity and mutual understanding, and to ensure that handovers between the different project stages and project teams were of good quality. One of the development teams arranged a common kick-off between the INF.3 team, researchers, and developers, which contributed to a mutual understanding. Both development teams ensured that several professions were involved from the start of the project, such as by ensuring the early involvement of the UX team, as mentioned in the previous section. As one UX designer stated: "This was a big investment for me. I got a lot of 
knowledge of the domain and learned a lot from the shadowing" (INF.3).

Furthermore, it was found that the understanding of the needs of the end users is important. As one of our informants stated: "The business tells you what is needed, and anything you do has to come from business. This means that the direct requirements come from the business, the foreman or the operator" (INF.4). The use of visualizations in meetings was found to support better communication between the participants to identify the actual needs of different user groups. Having arenas for communication about needs was also deemed as critical in the further roll-out processes: "For the implementation and roll-out phase in multiple projects with contract workers, it will be important to have meeting arenas to discuss and understand more about the tools" (INF.7). The need for such arenas was also emphasized by another informant from a development team:

The more users you get, the more feedback you get. ... Huge amounts of feedback ... and it's only positive that you get lots of feedback, but how do you screen it? How to make sure that what ends up on the backlog is what the company needs, and not just what they want. We need to look at this. (INF.12)

Communicating why an initiative is taken, and then how it fulfils the user needs across organizational levels, is a vital enabler for developing systems and tools that do what they are intended to do.

\subsection{Shared learning}

The fourth enabler, shared learning, addresses themes like training the trainers, and the focus of digitalization as part of continuous improvement work.

By analysing the interview data, we saw that "train the trainer" was regarded as a vital strategy for the success of the implementation phase in both studied projects. The term "train the trainer" refers to super-users training regular users in the use of the applications during the implementation stage of the project. The implementation stage had just been initiated when the interviews in this study were conducted, but the approach was an essential part of the implementation strategy:

We asked the super-users to train other users. This creates more empowerment. A key part was making sure they feel that they own the product. Therefore, it was really important to identify the right guys early in the process. We started out with a good mix of eager and positive people. People we thought were going to enable us; it's about the guys that are a bit curious. (INF.4)
We observed that this strategy led to good ambassadors at the floor level. After being involved in the project for a long period, the super-users became system experts and used their adopted skills to teach their colleagues. It was not expected that super-users should teach colleagues, but a lot of them took the initiative to do so. Some of them even arranged one-on-one training sessions for those struggling with the technology. This was a positive spill-over effect from the "train the trainer" approach, demonstrating that the super-user is an important role with implications for both the development and implementation at the floor level.

An example of super-users becoming good ambassadors and mentors for colleagues is the following quotation that describes situations where people were finding it hard to adapt to and learn the new technology:

There has been resistance among some individuals who do not want to use digital tools, who find it difficult. We have taken them aside and gone through difficulties and followed them up one and one. Walking through and repeating the tasks that the person should carry out. And at the end, things have gone fine... A one-on-one walkthrough is the best way to achieve this... they become a bit more comfortable with the situation, and you can explain it to them slowly, and then they understand it better. A lot of it is about lack of knowledge and insecurity. If you do this one-on-one, much of the insecurity disappears. (INF.15)

One of the project groups commented that this strategy alone would not be sufficient in a large-scale implementation:

Going into implementation, "train the trainer" is vital for us, but we also need some kind of muscles to do the training for larger groups. The philosophy is superusers out there who own the process, but at the same time they need help when we are going to train more and more users. We need to strengthen the ecosystem, all parts of the service. (INF.4)

This approach was supported by one of our informants who also indicated the need for good training practices: "Enough time should be allocated for training" (INF.7); "It is important to arrange meetings where people get to understand more - meeting arenas to discuss challenges with a roll-out across the entire company" (INF.7).

The understanding of digitalization as part of regular and continuous improvement of work is useful for the development and implementation phase, because a joint understanding would make a better baseline when commencing new practices: "A driver for a good process is to know the need to use digitalization as part of the improvement work you do to be competitive and survive as an industrial company" (INF.9); "Digitalization is being worked on systematically as an improvement proposal” (INF.10). One illustrative quote 
presents the basic idea that companies need to be alert and ahead of trends to survive: "Do it when we can, not when we have to" (INF.9).

The continuous nature of digitalization as a process of constant change therefore comes with a set of challenges. In the following sections, we consider the four barriers that we identified in the process of developing and implementing digital applications in the case company.

\subsection{Trusting the system}

The first barrier is trusting the system. It addresses issues such as compatibility with existing systems, trouble with the speed and stability of networks, system access, and data security.

In some software development projects, it is necessary to adapt or make the new technology work with existing software or infrastructure in the company. This was the case for one of the development projects in the case company:

There is a big and complex software system in the organization already. It's the background with all its advantages as well as drawbacks. There are just a few recourses (people) in the company that knows the system fully, how it works and how it is built. Without these recourses on the development team, we would be groping blindly. (INF.5)

At the beginning of every sprint, both teams are supposed to start working with tasks. The tasks might be defined, and you know how to solve it, but quite often the backend team needed a few days to figure out the existing software system before the rest could start their tasks. (INF.5)

Another finding related to infrastructure and the goal of becoming more efficient and competitive is the need for better collaboration across systems and increased sharing of information: "It's becoming more and more important to collaborate across systems in a simple way and to share information easily" (INF.8).

Infrastructure challenges, such as speed and stability, are negative for an implementation process. This has also been indicated in previous research. Technical problems, particularly software problems (crashes, software errors, delayed system reactions to user input, and software freezes) have been described as frequently occurring stressors when implementing ICT:

Apps and various apps, password issue, must log out and sign in. Goes up to several weeks without access due to login problem. Every single app requires a password. Up until now it has been a barrier when people go for one week waiting for passwords. Different intervals on passwords, etc. (INF.6)
Practical challenges are coverage, network, access, password trouble, etc. Server access - servers can withstand the pressure? (INF.7)

Other barriers that were emphasized by the informants were data security and trust. Having mobile applications for all operations in the manufacturing process raises the question of how data will be further used, stored, and analysed. The implementation process depends on the users trusting that their data will not be abused by any party for monitoring, surveillance or other unethical practices: "We have to make sure the users trust that the data will not be used for monitoring" (INF.9).

Furthermore, the access to the system by third-party developers was found to be a barrier. The case company is a large corporation with strict routines for supplier qualification, which includes those supplying IT services. In one of the applications, the case company collaborated with a small start-up company that was technically outstanding and suitable for the development job. However, when the project was about to move from a research and development phase of pilot implementation to a full-scale operational contract, it was challenging to get around the bureaucratic routines for purchasing agreements with a start-up with a limited track record: "There was a challenge with the company policy on the use of subcontractors with this start-up, and this can be a barrier to innovation" (INF.9).

\subsection{Understanding the benefits}

The second barrier identified by the analysis concerned understanding the benefits and highlighting barriers, such as putting the old tools away, measures of effectiveness, business cases, and return of investments.

When new tools are ready to be implemented, it seems like the old tools become a hindrance to implementation. New tools need to have the entire focus, meaning that if the old tools are still available, they will preclude the effectiveness of the new ones: "As long as one has the tool we are used to working with, it is more difficult to use the new" (INF.6); "It is easy to fall back to using the safe (old) tool if it is still available and possible" (INF.7). Another participant addressed this issue as follows:

Now [the new app] is used in addition too. The whole [project name] uses both. Both digital app and paper. One trusts too much what one did before. The truth is that this is not working financially right now, because now we are doing things twice. But in the long run it will be! (INF.1)

It seems as if new digital tools need a "wow" factor to kick start the implementation: "The product must be 
self-selling, if only slightly better - it is more difficult to get it implemented" (INF.1).

However, this is only part of the story when the workplace is still undergoing development and implementation. Due to problems with, for example, reliability, response time, lack of functionality, usability issues or login challenges, coexistence between new and old tools can make the operation more robust and less vulnerable to glitches in the digital technology. If it is decided to shut down all old tools during implementation, the company can face massive interruptions in production. One respondent described a situation where a department stopped using the new application and returned to working in the old way: "as time went on, people stopped using the mobile to report progress. Because it took too long compared to just ticking off the job package, like you did previously" (INF.13). Moreover, the non-digital tools provide properties that the digital applications do not, and vice versa. One informant mentioned the benefits of using large-sized paper drawings, a property the new digital application was unable to replace: "The app doesn't replace an A3 drawing" (INF.14).

Since digitalization projects are expensive, the company needs financial proof of the investment beforehand. However, it is difficult for some digitalization projects to show an instant effect because they involve work practices, people, and changes that need to be rooted in new work practices before it can be shown that there has been increased productivity and efficiency. Measures of effectiveness and the constant need to deliver business cases are a barrier to both the development and the implementation of digital projects. The following quotes illustrate this:

It is hard to prove that it will be a financial success. It needs a business case, but proving that this is a smart investment is difficult and heavy. Not everything can be proven economically. (INF.1)

It is challenging to realize the effects of [the digitalization projects]. Sometimes the effect is visible right away, while at other times we have to do something different to show the effects (for instance, change to several operators per team leader). (INF.8)

If you can create a business case that shows direct savings, it is easier to get permission for a digitalization initiative. It is difficult in practice to show short-term savings, but they are often a prerequisite for investments. The effects of digitalization initiatives are often composed factors and hard to isolate and quantify. (INF.9)

Effect measures and business cases showing short-term gains are often a prerequisite for the investment; since many digitalization projects can only show long-term benefits, this can act as a barrier.
Another finding is that it can be challenging to evaluate the success of a software development project, especially if there is limited data on key performance indicators available prior to the development or if a baseline study is missing. It can also be challenging to measure the effects of a new development if it also delivers functionality that is hard to quantify: "how do you quantify empowerment? We need to quantify what we can quantify, but it will also deliver other value which people benefit from" (INF.4).

\subsection{Perspectives of economics}

The third barrier addressed by our analysis is perspectives of economics, which relate to budget changes and economic conditions.

Big digitalization projects present challenges because they cost a lot of money, time, and effort. It is frustrating when all that money, time, and effort encounter budget cuts:

We are in for a strange period now, a lot of money was put in last year, this year a lot was cut. We are in times of economic instability. We cannot proceed with the project, without proving that it pays off. It's a bit of a shock to us that it's suddenly back to the base case, that one has to prove that things pay off before one gets started ... must now prove that it [digitalization project] will pay off. (INF.1)

For big and expensive projects, the financing is a real challenge. (INF.10)

Another economic condition that challenges the implementation process is the diversity in the workforce. It is almost impossible to show that digitalization project on the shop floor will be beneficial without involving contracted employees as well.

Separate hiring? The whole business idea is that anyone with a phone should have access. The idea is that [name of the app] should be for everyone, there should be no difference between hired and permanent employees. There is an ongoing process of translating it into Polish. Hiring is $80 \%$, and own employees only $20 \%$, so you have to think about the whole organization. It should not be differences between contracted and employed. This will fall through if it is not implemented to everyone. (INF.1)

Hired staff must enter the same platform. And when we see the challenges we have with passwords for our own operators, this becomes a big challenge. Must update password after 12 weeks. (INF.6)

One of the studied projects prepared an extensive longterm implementation plan that included several activities for dissemination and training, but eventually this did not 
receive funding for the implementation part. One informant summarized it as follows:

We knew we were going to face challenges that we haven't tackled well in the past. However, the plan did not receive funding, so instead we adopted more familiar "quick-and-dirty" approach where the use of "good" super-users has been central. (INF.12)

As a result, they had to improvise and find new and less expensive ways of implementing the application.

\subsection{Learning to manage scope}

Large-scale implementation is difficult. The company had experience with projects of different sizes. We observed a fear of failing when it came to implementation processes affecting many people. The following quotes from different participants highlight this challenge of scope:

Implementation has been incredibly difficult. We have always said it is difficult, but I just have to emphasize that it has been difficult - times 10! It is much more difficult than we thought. (INF.1)

Implementing things when many people intend to use them is a challenge. (INF.8)

The company relied on new work practices and more effective work, and it was dependent on a functional implementation process, despite such large-scale implementation being challenging:

I am afraid that the implementation is not going well, we have so many examples that it is not going well that it is all for nothing. We must maintain the pressure and be able to follow the implementation all the way; to implement and create new work practices. We risk that all this money is spent for nothing. Where it is most crucial [to implement it] is where it is also most difficult to implement. (INF.1)

Participation in large-scale implementation of digital applications is often in addition to operational responsibilities. It can be challenging to achieve a good balance between a digitalization project and core work tasks: "Enough time and resources have to be provided. People have $100 \%$ jobs, they are also asked to contribute to the improvement initiatives, without getting more time or resources" (INF.10).

Another aspect of this barrier is the scope of training. The case company has good experience with small-scale implementation where all participants have been involved in the entire process. When they have had a full participative approach, no training has been needed. However, large-scale training is much more challenging: "The level of differences and difficulties [learning new things] are greater than one thought in relation to training. We need training and more than we thought. Must spend time on training" (INF.1). It seems that the size of projects and the number of people involved require different strategies and training practices and that there is no "one-size-fits-all" solution. An analysis of the data indicates that this could act as a barrier in digitalization projects.

In large-scale implementation, managing user feedback acts as a barrier. For example, if 1,000 operators send in questions about the application and expect feedback, it becomes challenging if there is no structure to manage these questions. One participant commented on their help desk for IT questions:

The help desk is not updated on [name of app]. The help desk must know what is happening in the organization. We have three different levels when I flag a case, a software case is to be flagged through the help desk, but there they were not informed about it. (INF.6)

Another participant from the shop-floor level commented that this was a general challenge in the case company: "When there is information overload, we traditionally struggle to get information out to the line [floor level]" (INF.1). A third participant stated that there is also a need for feedback when the suggestions are not taken into account: "If $a$ proposal (digitalization as an improvement proposal) is not given priority, then it would have been nice to get feedback, as then there may be more suggestions too" (INF.10). Managing user feedback acts as a barrier.

\section{Discussion}

By conducting a case study, we have gained knowledge about enablers of and barriers to the development and implementation process in a manufacturing company and showed how modern STSD (in particular DD) can play out in digitalization projects. By analysing data from different stakeholders, we have found that, in a digitalization project, a set of factors will enable the process while others act as barriers, and that these enablers and barriers coexist in such processes and should not be treated as separate constructs. This coexistence is a highly relevant finding that show how important it is to investigate connections and interactions between relevant factors in situations where technology, work, and employees are understood as components that together constitute the organizational work system (De Sitter et al. 1997). In the studied process of digitalization, which involved the whole organizational system (the technology, work, enablers of the work, the organization of the work, and people), it was more about learning how to handle the coexistence and to find the right balance between enablers and barriers more than about finding ways to increase the 
enablers and reduce the barriers. Some enablers might also act as moderators of barriers. The analysis reveals that the enablers relevant to the development and implementation processes are shared trust, shared visual understanding, shared user perspectives, and shared learning. The relevant barriers are trusting the system, understanding the benefits, perspectives of economics, and learning to manage scope. In this section, we discuss the findings more thoroughly.

The main contribution of the enablers is the focus on establishing something shared. In STSD DD, many actors have shifted from one-directional communication ("tell" and "inform") to proper two-way dialogue (Gustavsen 2018). By having dialogue as a block in the foundation wall of the organization, digitalization can fulfil its unrealized potential. However, this requires understanding that technology, work, and employees are components that together constitute the organizational work system, and it needs to be studied in terms of how these components are connected, interact, and produce effects (De Sitter et al. 1997). Furthermore, digitalization is a social construct that is always partial and temporary, it results from specific decisions taken on different regulatory levels, and it interconnects with contemporary economic and social dynamics (Salento 2018). By analysing the data, we found practices indicating that the case study used both deliberations and discretionary coalitions and that it functions as different ways of DD. Shared trust, visual understanding, user perspectives, and learning are enablers relevant to realizing the potential of both deliberations and discretionary coalitions. For instance, we found that an extended collaboration with unions is an important way to elaborate shared trust in the development and implementation process of digitalization. The industrial relations in the case company follows the Norwegian industrial relations principles of high trust, low conflict, predictability, and it extends dialogue and the strength of the local level within both the multi-level collective bargaining system and the single-level system of unions representing workers on all organizational levels (Ravn and Øyum 2018). More specifically, the finding of shared trust is also supported by previous research demonstrating the importance of exchange of information between different participants, both horizontally (on the shop floor, across the entire process) and vertically (between different hierarchy levels) (Gröger et al. 2013), of honesty about the aim of a digital intervention, and of providing workers with correct information (Lacueva-Pérez et al. 2018).

At the same time, trusting the system acts as a barrier. Compatibility with existing systems, the speed and stability of networks, system access, and data security were themes challenging the use of digital applications. Our participants experienced similar issues to those found in previous research: technical problems leading to interruptions, added time pressure, and the negative effects of multitasking
(Körner et al. 2019). These barriers can lead to interruption of flow and a slowdown of the work process, which, in turn, increases the time pressure and perceived work stress. The more technical issues addressed here can have widespread consequences. It is not straightforward to adapt the new technology work to a company's existing software or infrastructure. The implementation process depends on the users trusting the system and that their data will not be abused by another party for monitoring, surveillance, or other unethical practices. When there is a lack of awareness about this and how to handle or reduce these challenges, they will affect the development and, especially, the implementation of digital applications. Shared trust and shared user perspectives are particularly important enablers that help deal with such barriers.

Applying a theoretical frame of modern STSD has proved useful in understanding the results. Work, organization, and people are not separate domains; rather, aspects of work should be studied through a multiple stakeholder approach (Mohr and Amelsvoort 2018). Our data reveal contrasting views relating to the barrier of "understanding the benefits". Even though all the informants agreed on the importance of being able to describe in detail the benefits that would be obtained by implementing the new system, they did not agree on what to do with the old system. Whereas managers viewed the coexistence of the old system as an obstacle to implementation, people in more operational roles highlighted the benefits of being able to have the old system as a back-up that also contained additional information. Technical problems when introducing new digital implications have previously been found to lead to interruptions, added time pressure, and multitasking in a negative way (Körner et al. 2019). At the same time, showing commitment to a new system at both the corporate and the shop-floor levels has previously been found to be a key enabler of digitalization (Alexopoulos et al. 2018). Therefore, companies will need to balance the need for a back-up in the form of the old tools with the loyalty to new systems, at least in a period of time.

Previous research has argued that a worker-centred approach and user involvement are important principles in the processes of developing digital tools (Leyer et al. 2019; Signoretti et al. 2019; Vilkki 2010). However, we find that the principle of involvement referred to in the previous literature is often too general. Worker-centred approach and user involvement can act as two forms of DD. As part of DD we see that it also generates more usable solutions and act as practices where the user needs, and expectations are elaborated. Our finding on shared user perspectives elaborates the importance of flexible and versatile involvement, indicating that organizations need to involve different stakeholders in digitalization projects depending on the purpose of the project and the end users. Good involvement practices enhance user acceptance and makes system adoption easier 
by generating more usable solutions (Mumford 2006; Ritter et al. 2014). Moreover, to better understand the underlying problems and what the users really want, agile development (Ximenes et al. 2015) combined with flexible and versatile involvement impact the success of developing and implementing digital applications. There is also a growing interest in combining agile development with user-centred approaches to improve the collaboration between designer/ developers and users (Abelein and Paech 2015). We found that by including designers more locally, structures were created that enabled users to communicate their needs. This is in line with what modern STSD says about local theory (Elden 1983; Raelin 2012). Important strengths of DD are the closeness to the field and the idea that collaboration and solutions should be created locally. User-driven change are crucial in DD together with proper two-way dialogue (Gustavsen 2018). An observed consequence of increased user involvement in development and implementation processes is that it also led to the challenge of managing extensive user feedback. This might act as a barrier to implementation and continuous improvement of the application. Finding ways to balance user involvement and establishing necessary arenas to handle improvement suggestions could be one strategy to handle this dilemma.

Digital applications have previously been found to strengthen the empowerment of the individual if the individual receives the proper information, guidance, and feedback from colleagues and supervisors (Leyer et al. 2019). We contribute to this field by adding findings about the importance of well-functioning feedback-loops that also include the designers/developers. It is important not to ignore the relationship between those who have the power to design digital applications - that is, the designer/developers-and the users (Salento 2018). Visualization facilitates participation and provides participants with a better understanding of both the process and the product. It also gives participants more confidence to share and discuss important details and artefacts relating to their working day, which has an impact on the application's content and layout. Shared visual understanding acts as an enabler that strengthens the power of the other enablers. Overall, to develop shared user perspectives and a shared visual understanding, we argue that deliberations and discretionary coalitions need to be shown in practice. Although all participants in this study agreed that new digital applications achieve benefits like increased transparency and agility of manufacturing operations, proactive optimization by dynamically generating action recommendation, and knowledge sharing and delivery of (near-)real-time information to workers and supervisors (e.g., Gröger et al. 2016; Leyer et al. 2019), implementing such applications is difficult.

One way to handle challenging implementation is to adopt the "train the trainer" perspective, as it is not always easy or practical to have training sessions with everyone on the floor level. We know that training is important. Lack of adequate training has been shown to increase the experience of work stress (Körner et al. 2019). We found that by devoting time to training, positive spill-over effects for both the development and implementation at the floor level were developed as super-users become good ambassadors and informal mentors of colleagues. Another relevant finding is that, to establish shared learning as an enabler in a digitalization process, the organization needs a shared focus so that the digitalization becomes part of the organization's continuous improvement work and something that will benefit stakeholders, the social system, and technology.

\subsection{Implications for research}

This study contributes to the literature by providing a rich empirical description of the contemporary phenomenon of digitalization. The paper describes in detail the perceived enablers of and barriers to digitalization within a large ETO manufacturing company. There is a need for more empirical research within manufacturing, as some find it to be less accessible and visible to scholars (Salento 2018). This paper has also taken a holistic view of digitalization by studying both the development and the subsequent implementation processes. The development and implementation phases are often studied separately, but they are highly related, and should be examined together. This is in line with Kuusisto (2017), who called for more "big picture" studies on the process and effects of digitalization. As an example, we found that the work practices in the development phase, through active use of visualization, enabled users to become more involved and take larger responsibilities than originally intended in the implementation phase. A further implication of this research is that the use of modern STSD as DD can provide a useful frame of reference for understanding digitalization. A modern STSD perspective is vital for understanding the needs of humans and social systems, and for keeping these needs in balance with the advantages and challenges of digital technology (Claussen et al. 2019; Pasmore et al. 2018). In our study, we found the concept of DD, deliberations, and discretionary coalitions to be vital components for establishing the necessary shared trust. An extended collaboration with unions allowed a broad agenda of discussions and learning points throughout the process. We observed that all informants, regardless of position, appreciated this extended collaboration that was rooted in their company's different DD practices.

\subsection{Implications for practice}

This research has practical implications as it provides information about how one can increase operational transparency 
with digital applications. There are three key takeaways for stakeholders of a digitalization process in manufacturing. First, it is vital to understand and strengthen the role of the key enablers identified in this paper (trust, visualization, user perspective, and learning). Second, managers should observe and identify barriers in their own organizations, relating to both technical and social aspects (system issues, perceived benefits, economic aspects, and managing scope). Third, some of the enablers described in this paper can serve managers as helpful tools to approach the expected barriers to digitalization. These three implications are described in further detail here.

When a manufacturing company embarks on a digitalization journey, it is vital to focus on building a shared trust across roles and levels of the company. Achieving an early common understanding about the purpose and process is vital. For instance, open communication and extended collaboration with unions are found to be helpful in this regard. Visualization can facilitate and enhance such participation. Managers should pay special attention to user involvement and communicating user needs. Rapid release of functionality in line with agile development methods can help to ensure that the project stays on the right track. Finally, managers should strengthen learning strategies by involving users as trainers. The involvement of users throughout the entire process, from early design to full implementation, such as with a "train the trainer" strategy, can contribute to increasing the number of ambassadors for the new tools, which in turn increases the chance of success. The topics addressed under the enablers shared trust, shared visual understanding, shared user perspectives and shared learning presented in Fig. 1 are in line with different traditions in modern STSD and can function as good guidance. However, managers need to pay attention to the identified barriers to digitalization. They should also pay special attention to describing the prospective benefits and effects of the project. Identifying the right elements of the business case and then measuring the effect have proved to be challenging, and they must be addressed early on. Technical issues, such as compatibility with other systems, speed, stability, access, and security, are potential obstacles to achieving the necessary trust in a new system. Further, managers should pay special attention to economic conditions and factors that can influence changes in the budget for an ongoing project. Finally, a main barrier to the digitalization process is managing large-scale implementation, with immense volume of user feedback and a significant need for training throughout the organization.

The different aspects of digitalization processes are highly related and intertwined. Some of the identified enablers can be used as measures to mitigate and reduce some of the potential barriers. Early involvement of users can help better understand the potential benefits and business case of the project. Establishing an understanding among the top management that digitalization requires a long-term and continuous focus on improvement can reduce the risks of budget cuts and unforeseen events in the project. Working with visualization tools and methods can assist in learning and training activities during full-scale implementation.

However, we have also identified perceived enablers that simultaneously reinforce a barrier. An example of this is user involvement. Having extensive user involvement across multiple arenas throughout the project can contribute to generating a vast amount of user feedback that can prove difficult to manage. Therefore, companies need to find a balance between establishing sufficient arenas for input and participation, and finding the means to handle feedback, suggestions, and requests effectively. A feedback system that collapses due to its scale can do more harm than good.

Applying the factors described in this paper can provide tangible effects for companies. The preliminary results of the digitalization initiatives of the case company show signs of increased operator autonomy. More time was freed to work on core tasks. The foremen spent less time on administration, planning, and reporting. As a consequence, there was less overtime and time pressure for the foremen. The company received live updates about progress and became more accurate in planning their project team.

\section{Concluding remarks}

This study is based on a single case company, in which two digitalization projects have been examined by thematic analysis. This method involves a risk of undetected biases and misinterpretations. Although measures were taken to mitigate these risks (interviewee access, multiple review rounds of constructs, and outside researcher perspectives), the importance of certain findings might nevertheless have been over- or understated. Therefore, we call for more research that focuses on both the development and the implementation stages, especially from a longitudinal perspective, to gain more knowledge about the agile changes from implementation of digital tools to their functioning in practice. The continuous nature of improving and refining core digital applications and systems makes the timescale of such studies important. Is it possible to establish the effects of a system if the system is constantly evolving? We therefore encourage future research to study the large-scale implementation processes of digitalization in manufacturing. Further studies should examine other cases with similar challenges to gain more knowledge about the development and implementation processes of companies in digital transformation. We encourage the use of a multidisciplinary approach to such studies to understand both the social and the technical aspects of work systems. Organizational theory can benefit from concepts of agile methods and design thinking to expand 
the understanding of users' roles. Studies from information technology and operations management can contribute to a better understanding of the critical aspects required to achieve the necessary trust in the use of new tools and applications.

There is no one-size-fits-all solution in digitalization processes. In this study, we have found that, when developing and implementing digital applications, shared trust, shared visual understanding, shared user perspectives, and shared learning act as enablers and trusting the system, understanding the benefits, perspectives of economics, and learning to manage scope act as barriers. More importantly, we found that enablers and barriers coexist and should not be treated as separate constructs. Implementation is the most challenging phase as there is no easy way to establish new work practices. By focussing on the coexistence of enablers and barriers, together with concepts and practices elaborated in modern STSD DD, organizations can come a step closer to obtaining the competitive effects of digitalization and to being sufficiently robust to handle ongoing changes in the modern working life. The findings contribute with three key takeaways for stakeholders of a digitalization process in manufacturing. First, it is vital to understand and strengthen the role of the key enablers identified in this paper. Second, managers should observe and identify barriers in their own organizations, relating both to technical and social aspects. Third, some of the enablers described in this paper can serve managers as helpful tools to approach the expected barriers to digitalization. This paper also challenges the research literature by arguing that research conducted on digitalization that sets new standards and premises for the work life in industry needs to use up-to-date socio-technical design concepts and theories.

Author contributions All authors have contributed with the interviews, data analysis, and writing of the article.

Funding Open access funding provided by SINTEF AS.. The project has been funded by the Research Council of Norway $(256754 / \mathrm{O} 20$ \& 309810).

Availability of data and material (data transparency) Anonymized transcripts of the interviews can be accessed by contacting the corresponding author.

\section{Declarations}

Conflict of interest No conflicts of interest.

Open Access This article is licensed under a Creative Commons Attribution 4.0 International License, which permits use, sharing, adaptation, distribution and reproduction in any medium or format, as long as you give appropriate credit to the original author(s) and the source, provide a link to the Creative Commons licence, and indicate if changes were made. The images or other third party material in this article are included in the article's Creative Commons licence, unless indicated otherwise in a credit line to the material. If material is not included in the article's Creative Commons licence and your intended use is not permitted by statutory regulation or exceeds the permitted use, you will need to obtain permission directly from the copyright holder. To view a copy of this licence, visit http://creativecommons.org/licenses/by/4.0/.

\section{References}

Abelein U, Paech B (2015) Understanding the influence of user participation and involvement on system success: a systematic mapping study. Emp Soft Eng 20:28-81

Abrell T, Pihlajamaa M, Kanto L, Brocke J, Uebernickel F (2015) The role of users and customers in digital innovation: insights from B2B manufacturing firms. Inf \& Man 53:324-335. https:// doi.org/10.1016/j.im.2015.12.005

Alexopoulos K, Sipsas S, Xanthakis E, Makris S, Mourtzis D (2018) An industrial Internet of things based platform for contextaware information services in manufacturing. Int $\mathrm{J}$ of Com Integrated Manu 31:1111-1123. https://doi.org/10.1080/09511 92X.2018.1500716

Braun V, Clarke V (2006) Using thematic analysis in psychology. Qual Res Psychol 3:77-101. https://doi.org/10.1191/14780 88706qp063oa

Caruso L (2018) Digital innovation and the fourth industrial revolution: epochal social changes? AI \& Soc 33:379-392. https://doi. org/10.1007/s00146-017-0736-1

Cherns A (1976) The principles of sociotechnical design. Hum Relat 29:783-792

Claussen T, Haga T, Ravn JE (2019) Socio-technics and beyond: an approach to organisation studies and design in the second machine age: introductory editorial. Eur J of Workplace Inn, Special Issue 4:99-122

de Sitter LU, den Hertog JF, Dankbaarl B (1997) From complex organizations with simple jobs to simple organizations with complex jobs. Hum Rel 50:497-534. https://doi.org/10.1177/ 001872679705000503

Eisenhardt KM, Graebner ME (2007) Theory building from cases: opportunities and challenges. AMJ 50:25-32

Elden M (1983) Client as consultant. Work reform through participative research GBOE 2:136-147. https://doi.org/10.1002/npr. 4040020205

Ferreira JJM, Fernandes CI, Ferreira FAF (2019) To be or not to be digital, that is the question: firm innovation and performance. J Business Res 101:583-590. https://doi.org/10.1016/j.jbusres. 2018.11.013

Gorecky D, Schmitt M, Loskyll M, Zühlke D (2014) Humanmachine interaction in the industry 4.0 era. In: 12th IEEE International Conference on Industrial Informatics, Porto Alegre, 289-294. https://doi.org/https://doi.org/10.1109/INDIN.2014. 6945523

Gröger C, Hillmann M, Hahn F, Mitschang B, Westkämper E (2013) The operational process dashboard for manufacturing. Procedia CIRP 7:205-210. https://doi.org/10.1016/j.procir.2013.05.035

Gröger C, Stach C, Mitschang B, Westkämper E (2016) A mobile dashboard for analytics-based information provisioning on the shop floor. Int J Com Integrated Manu 29:1335-1354. https://doi.org/ 10.1080/0951192X.2016.1187292

Gustavsen B (2018) Democratic dialogue. In: Mohr BJ, van Amelsvoort $\mathrm{P}$ (eds) Co-creating humane and innovative organizations: evolutions in the practice of socio-technical system design. Global STS-D Network Press, Portland, pp 186-200

Hackman JR, Oldham GR (1980) Work redesign. Addison-Wesley, Reading MA 
Haga T (2019) Can unconventional socio-technical system approach open the way to new solutions and new understanding? Eur J Workplace Inn, Special Issue 4:161-175

Hecklau F, Galeitzke M, Flachs S, Kohl H (2016) Holistic approach for human resource management in Industry 4.0. Procedia CIRP 54:1-6. https://doi.org/10.1016/j.procir.2016.05.102

Kagermann H, Wahlster W, Helbig J (2013) Recommendations for implementing the strategic initiative Industrie 4.0: securing the future of German manufacturing industry (Final report from the Industrie 4.0 Working Group). National Academy of Science and Engineering, Munich

Karasek R (1997) Demand/control model: a social-emotional, and psychological approach to stress risk and active behavior development. In: ILO encyclopedia of occupational health and safety: 34.6-34.14. Geneva: ILO

Körner U, Müller-Thur K, Lunau T, Dragano N, Angerer P, Buchner A (2019) Perceived stress in human-machine interaction in modern manufacturing environments: results of a qualitative interview study. Stress Health 35:187-199. https://doi.org/10.1002/smi.2853

Kuusisto M (2017) Organizational effects of digitalization: a literature review. IJOTB 3:341-362

Lacueva-Pérez FJ, Hannola L, Nierhoff J, Damalas S, Chatterjee S, Herrmann T, Schafler M (2018) Comparing approaches for evaluating digital interventions on the shop floor. Technologies 6:1-22. https://doi.org/10.3390/technologies6040116

Landmark AD, Andersen TK, Kamsvaag PF (2019) Using STSD for understanding the implementation of automation in organisations, Eur J Workplace Inn. Special Issue 4(2):253-271

Leyer M, Richter A, Steinhüser M (2019) Power to the workers: Empowering shop floor workers with worker-centric digital designs. Int J Ope Pro Man 39:24-42. https://doi.org/10.1108/ IJOPM-05-2017-0294

Mazali T (2018) From industry 4.0 to society 4.0, there and back. AI \& SOC 33:405-411. https://doi.org/10.1007/s00146-017-0792-6

Mierlo, van, H, Rutte CG, Vermunt, JK, Kompier M, Doorewaard JACM, (2006) Individual autonomy in work teams: the role of team autonomy, self-efficacy, and social support. EJWOP $15: 281-299$

Mohr BJ, van Amelsvoort P (2018) The future of STS-D. In: Mohr $\mathrm{BJ}$, van Amelsvoort $\mathrm{P}$ (eds) Co-creating humane and innovative organizations: evolutions in the practice of socio-technical system design. Global STS-D Network Press, Portland, pp 44-352

Mumford E (2006) The story of socio-technical design: reflections on its successes, failures and potential. ISJ 6:317-342. https://doi. org/10.1111/j.1365-2575.2006.00221.x

Orlikowski WJ (1996) Improvising organizational transformation over time: A situated change perspective. Inf Syst Res 7:63-92

Parviainen TM, Kääriäinen J, Teppola S (2017) Tackling the digitalization challenge: how to benefit from digitalization in practice. IJISPM 5:63-77

Pasmore W, Winby S, Mohrman SA, Vanasse R (2018) Reflections: sociotechnical systems design and organization change. J Cha Man 19:67-85. https://doi.org/10.1080/14697017.2018.1553761

Prinz C, Morlock F, Freith S, Kreggenfeld N, Kreimeier D, Kuhlenkötter B (2016) Learning factory modules for smart factories in Industrie 4.0. Procedia CIRP 54:7-12. https://doi.org/10.1016/j. procir.2016.05.105
Raelin JA (2012) Dialogue and deliberation as expressions of democratic leadership in participatory organizational change. JOCM 25:7-23

Ravn JE (2019) Minimal critical specification and collective organizational redesign. Eur J Workplace Inn, Special Issue 4:214-230

Ravn JE, Øyum L (2018) Towards "multi-collar" unionism: cases of trespassing professionals in Norwegian industrial relations. Eco Ind Dem, online. https://doi.org/10.1177/0143831X17743794

Ritter FE, Baxter GD, Churchill EF (2014) Foundations for designing user-centered systems. What system designers need to know about people. London, Springer-Verlag

Salento A (2018) Digitalisation and the regulation of work: theoretical issues and normative challenges. AI \& Soc 33:369-378. https:// doi.org/10.1007/s00146-017-0738-Z

Signoretti I, Marczak S, Salerno L, de Lara A, Bastos R (2019) Boosting agile by using user-centered design and lean startup: a case study of the adoption of the combined approach in software development. In: ACM/IEEE International Symposium on Empirical Software Engineering and Measurement (ESEM), Porto de Galinhas, Recife, Brazil: 1-6, https://doi.org/10.1109/ESEM.2019. 8870154

Thun S, Kamsvåg PF, Kløve B, Seim E, Torvatn H (2019) Industry 4.0: whose revolution? The digitalization of manufacturing work processes. NJWLS 9:39-57. https://doi.org/https://doi.org/10. 18291/njwls.v9i4.117777

Tortorella G, Miorando R, Caiado R, Nascimento D, Staudache, AP (2018) The mediating effect of employee's involvement on the relationship between Industry 4.0 and operational performance, Total Qua Man Bus Exc. Online version. https://doi.org/10.1080/ 14783363.2018.1532789

Tynes, T, Sterud, T, Løvseth EK, Johannessen HA, Gravseth HMU, Bjerkan AM, Bakke, B, Aagestad C (2018) Faktabok om arbeidsmiljø og helse 2018. Status og utviklingstrekk [Facts about working environment and health 2018. Status and development features] (STAMI-Research report)

Valenduc, G, Vendramin, P (2016) Work in the digital economy: sorting the old from the new. Working paper, European Trade Union Institute (ETUI). 2016.03: 5-50. http://hdl.handle.net/2078.1/ 173373

van Eijnatten FM (1998) Developments in socio-technical systems design (STSD). Handbook of work and organizational psychology, vol 4. Psychology Press, Hove, pp 61-88

Vilkki K (2010) When agile is not enough. International conference on lean enterprise software and systems. Springer, Berlin and Heidelberg, pp 44-47

Ximenes BH, Alves IN, Araújo CC (2015) Software project management combining agile, lean start up and design thinking. International conference of design, user experience, and usability. Springer, Cham, pp 356-367

Yin R (2009) Case study research: design and methods. SAGE Publications, London

Publisher's Note Springer Nature remains neutral with regard to jurisdictional claims in published maps and institutional affiliations. 